\title{
Scanning Based Induction Heating for AISI 4340 Steel Spline Shafts-3D Simulation and Experimental Validation
}

\author{
Habib Hammi, Abderrazak El Ouafi, Noureddine Barka, Ahmed Chebak \\ Mathematics, Computer Science and Engineering Department, University of Quebec at Rimouski, Rimouski, Canada \\ Email: Abderrazak_ElOuafi@uqar.ca
}

How to cite this paper: Hammi, H., El Ouafi, A., Barka, N. and Chebak, A. (2017) Scanning Based Induction Heating for AISI 4340 Steel Spline Shafts-3D Simulation and Experimental Validation. Advances in Materials Physics and Chemistry, 7, 263-276. https://doi.org/10.4236/ampc.2017.76021

Received: March 18, 2017

Accepted: June 17, 2017

Published: June 20, 2017

Copyright (c) 2017 by authors and Scientific Research Publishing Inc. This work is licensed under the Creative Commons Attribution International License (CC BY 4.0).

http://creativecommons.org/licenses/by/4.0/

\section{c) (i) Open Access}

\begin{abstract}
This paper presents an investigation of non-stationary induction heating process applied to AISI 4340 steel spline shafts based on 3D simulation and experimental validation. The study is based on the knowledge, concerning the form of correlations between various induction heating parameters and the final hardness profile, developed in the case of stationary induction heating. The proposed approach focuses on analyzing the effects of variation of frequency, power and especially scanning speed through an extensive 3D finite element method simulation, comprehensive sensitivity study and structured experimental efforts. Based on coupled electromagnetic and thermal fields analysis, the developed 3D model is used to estimate the temperature distribution and the hardness profile. Experimentations conducted on a commercial dual-frequency induction machine for AISI 4340 steel splines confirm the feasibility and the validity of the proposed modelling procedure. The 3D model validation reveals a great concordance between simulated and measured results, confirms that the model can effectively be used as framework for understanding the process and for assessing the effects of various parameters on the hardening process quality and performance and consequently leads to the most relevant variables to use in an eventual hardness profile prediction model.
\end{abstract}

\section{Keywords}

Induction Heating, Non-Stationary Induction Heating, Spline Shafts, Hardness Profile, Temperature Distribution, Finite Element Method, Induction Heating Parameters, Sensitivity Study, Prediction Model

\section{Introduction}

Many industries today, especially aerospace and automotive manufacturers, re- 
quire parts that are reliable in term of fatigue life and resistance. A spline, for example, is exposed for the majority of its lifetime to corrosion, loads, friction, wear, etc. To address these problems, engineers have introduced processing plans that aim not only to harden the part, but also to extend its lifetime so as to increase the reliability of the mechanical products.

One of the best processes is induction hardening, which is used to bond, harden or soften metals or other conductive materials. It offers an attractive combination of speed, consistency and control. The basic principle of induction heating has been applied since the 1920s, and during World War II, the technology has been developed rapidly to meet the urgent wartime requirement for a fast and reliable process to harden metal engine parts. What makes induction heating unique is the contactless heat transfer between the coil and the part, and most importantly the speed of the process. Induction heating relies on radio frequency (RF) energy, so heat is transferred to the part via electromagnetic waves and the inductor itself does not get hot. This leads to a highly repeatable and reliable process.

When an alternating current is applied to the primary coil of a transformer, an alternating magnetic field is created. According to Faraday's Law, if the secondary coil of the transformer is located within the magnetic field, an electric current will be induced. In our setup, the coil is the primary winding of the transformer and the part, located inside the electromagnetic field, is the secondary winding of the transformer. Therefore, circulating eddy currents are induced within the part in question. These eddy currents flow against the electrical resistivity of the metal, generating localized heat. This heating is called the Joule effect, referring to Joule's first law. In induction heating process, there is no contact between the inductor and the part, and therefore no combustion gases. The material to be heated can be located in a setting isolated from the power supply: submerged in a liquid, covered by isolating substances, in gaseous atmospheres or even in a vacuum.

Induction heating of the surface presents several advantages over other heat treatment methods, including high repeatability regarding the hardened layer quality, short heat treatment times, and easy incorporation into automated manufacturing processes [1]. Adding to that, compressive residual stresses are generated along with the hardened depth after induction hardening [2]. The efficiency of an induction heating system for our application depends on several factors: the used frequency, the capacity of the power supply, and most importantly, the scanning speed. The induction heating of splines was previously evoked in the work done by the authors, but in this case the spline was stationary and there was no scanning involved [3] [4]. All of the induced power and heat were concentrated in a single region in the spline.

In this work, 3D modelling and simulation, structured experimental efforts and improved statistical analysis tools are used to evaluate the effects of power, frequency variation and particularly scanning speed on the hardness profile. The model experimental validation is conducted on a commercial dual-frequency 
induction machine for AISI 4340 steel splines. The validated 3D model is used to simulate various process parameters and conditions effects and to estimate the temperature distribution as well as the hardness profile attributes. ANOVA is also used to evaluate the contribution of each parameter in temperature and hardness profile attributes variations. Based on these results, predictive models are established.

\section{3D Modelling Development}

The spline used in this work is made out of AISI 4340 steel which is the best used for splines, gears, shafts, and other structural parts. The spline has a $25 \mathrm{~mm}$ diameter with an internal diameter of $21 \mathrm{~mm}$ and is enrolled with a $27 \mathrm{~mm}$ coil made of copper as illustrated in "Figure 1". Hence, the gap between the part and the coil is fixed at $1 \mathrm{~mm}$. The spline should be moving along $\mathrm{z}$-axis with a velocity $V$ that we will vary to study velocity effects on hardened profile. The hardened region is supposed to be inside the electromagnetic considering the part motion. Because the spline is composed of 12 teeth, and thanks to the circular symmetry, only one twelfth of the spline is studied by simulation. This will shorten the calculation time and the software efforts to give precise results [5] [6] [7] [8] [9].

\subsection{Parameters Control}

A convergence study was conducted and revealed that the best mesh size in terms of calculation time and precision of results is equal to $0.5 \mathrm{~mm}$. The power delivered by the coil was varied around $26 \mathrm{~kW}$. Many tests were done to find that a proper hardness profile starts to appear with values greater than $23 \mathrm{~kW}$. A frequency of $200 \mathrm{kHz}$ was chosen for the simulation and the scanning speed was set to $V=10 \mathrm{~mm} / \mathrm{s}$. This resulted in a hardened region as the temperature reached the level needed for austenite formation, followed by a hardened layer with the formation of martensite after quenching.

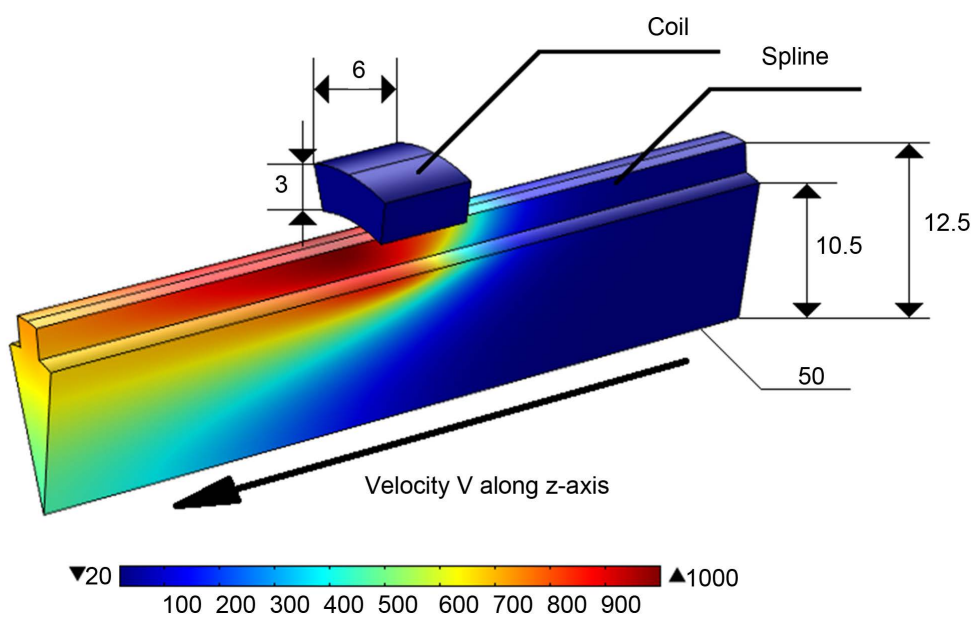

Figure 1. 3D Spline model with dimensions (in $\mathrm{mm}$ ) and temperature distribution (in ${ }^{\circ} \mathrm{C}$ ). 
The materials used in the simulation were air for the surroundings, cooper for the coil, and AISI 4340 steel for the spline. The AISI 4340 steel is characterized by a relative permeability, an electrical conductivity, a heat capacity and a thermal conductivity that are determined as a function of temperature over a specific time lapse during the simulation. Four interpolation functions were established to control the electromagnetic properties of the AISI 4340 steel. External current density was applied to the coil, and its geometric vector has $\mathrm{x}$-axis and a $\mathrm{y}$-axis coordinates in the 3D space. COMSOL Multiphysics software was used to solve Maxwell's equations which can be written as follows:

$$
\begin{gathered}
\nabla \times H=J+\partial D / \partial t \\
\nabla \times E=-\partial B / \partial t \\
\nabla \cdot B=0 \\
\nabla \cdot D=\rho^{\text {charge }}
\end{gathered}
$$

where $E$ is electric field intensity, $D$ is electric flux density, $H$ is magnetic field intensity, $B$ is magnetic flux density, $J$ is conduction current density, and $\rho^{\text {charge }}$ is electric charge density. Special symbols like $\nabla \cdot$ and $\nabla \times$ are popular in vector algebra and are useful to reduce an expression of particular differential operation without having to carry out the details: $\nabla U=\operatorname{grad} U, \nabla \cdot U=\operatorname{div} U$ and $\nabla \times U=\operatorname{curl} U$. In this part, we used the Fourier equation as it is written in this form:

$$
c \gamma \partial T / \partial t+\nabla \cdot(-k \nabla T)=\dot{Q}
$$

where $T$ is temperature, $\gamma$ is the mass density of the metal, $c$ is the specific heat, $k$ is the thermal conductivity of the metal and $Q$ is the heat source density induced by eddy currents per unit time in a unit volume. The system to be solved is given by:

$$
\begin{aligned}
& j \omega \sigma(T) A+\nabla \times\left(\mu^{-1} \nabla \times A\right)=J_{0} \\
& \rho C_{p} \partial T / \partial t-\nabla \cdot k \nabla T=Q(T, A)
\end{aligned}
$$

where $\rho$ is the mass density, $C_{p}$ is the specific heat capacity and $J_{0}$ is the source current density. The translational motion is described by Equation (5) and a dynamic vector $u$ that can be written as:

$$
\begin{aligned}
& \rho C_{p} u \cdot \nabla T=\nabla \cdot(k \nabla T)+Q \\
& U=u_{\text {trans }}=V_{z} \cdot z[\mathrm{~mm} / \mathrm{s}]
\end{aligned}
$$

One of the major features of induction heating computation deals with the fact that both the electromagnetic and the heat transfer phenomena are tightly coupled thanks to the interrelated nature of the material properties. First, specific heat, thermal conductivity, and electric resistivity are functions of the temperature. Second, magnetic permeability is a function of magnetic field intensity, temperature, and frequency. The multiphysics and the coupling aspects of the application are described by the system of equations below.

$$
\rho C_{p} u \cdot \nabla T=\nabla \cdot(k \nabla T)+Q_{e}
$$




$$
\begin{gathered}
Q_{e}=Q_{r h}+Q_{m l} \\
Q_{r h}=1 / 2 \operatorname{Re}\left(\mathrm{J} \cdot E^{*}\right) \\
Q_{m l}=1 / 2 \operatorname{Re}\left(i \omega B \cdot H^{*}\right)
\end{gathered}
$$

In this system of equations, both electric and magnetic fields are described, as well as the equation that links them to the heat produced. Scanning velocity is also shown and has an effect on the heat induced in the spline.

\subsection{Martensitic Formation}

The simulation was done using the mesh size, frequency, induced current density, and velocity most suitable for producing the proper hardened profile. However, before analyzing the results, some theoretical study of microstructure should be done.

AISI 4340 alloy steel is a low alloy steel that contains iron (95.195\% - 96.33\%), nickel $(1.65 \%-2 \%)$, chromium $(0.7 \%-0.9 \%)$, manganese $(0.6 \%-0.8 \%)$, carbon $(0.37 \%-0.43 \%)$, molybdenum $(0 \%-2 \%-0.3 \%)$, silicon $(0.15 \%-0.3 \%)$, sulfur $(0.04 \%)$ and phosphorous $(0 \%-0.35 \%)$. This steel is heat treated above $830^{\circ} \mathrm{C}$ followed by quenching in oil. It is used mainly in power transmission gears and shafts, aircraft landing gears, and other structural parts. The AISI 4340 steel has a raw non-martensitic microstructure that appears in "Figure 2", bottom right. This structure is characterized by its ease of bending under high stresses and its easiness to be corrosive. After the induction hardening is applied, a fine hardened surface layer appears showing a martensitic microstructure that is seen in "Figure 2", top right. Martensite is formed in carbon steels by the rapid cooling (quenching) of austenite at a high enough rate that carbon atoms do not have time to diffuse out of the crystal structure in large enough quantities to form cementite $\left(\mathrm{Fe}_{3} \mathrm{C}\right)$. As a result, the face-centered cubic austenite transforms to a

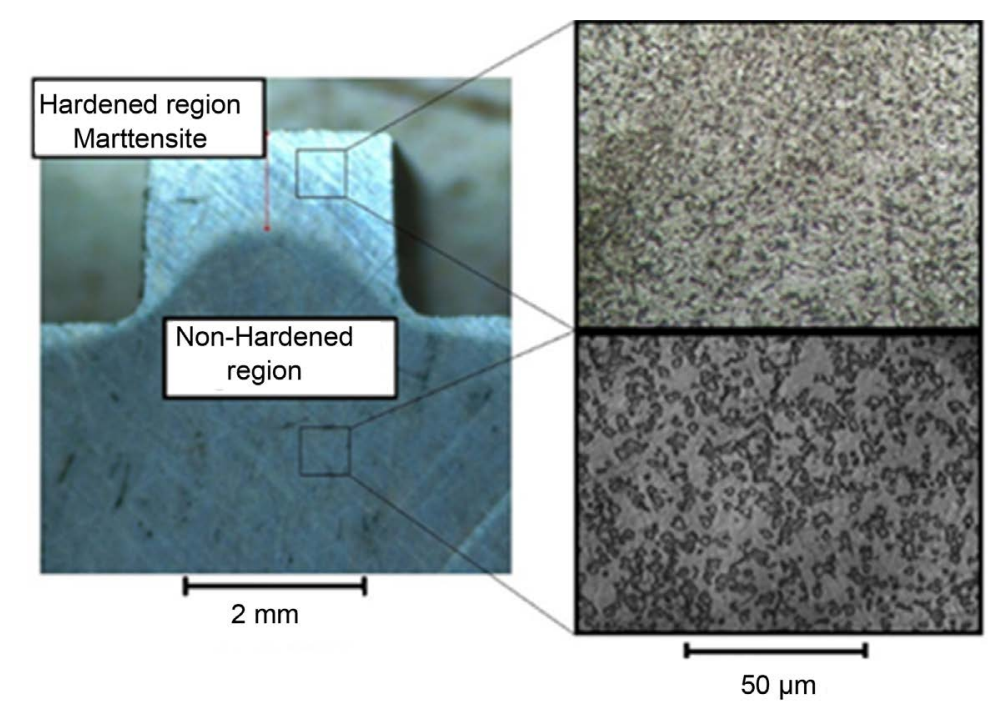

Figure 2. Cross section of the Hardened spline tooth (left), microstructure of the Hardened surface (top right) and microstructure of the raw material (bottom right). 
highly strained body-centered tetragonal form of ferrite that is supersaturated with carbon. The shear deformations that result produce large numbers of dislocations, which is the primary strengthening mechanism in steels.

\section{Predicted versus Measured Results}

The simulation was done with a frequency equal to $200 \mathrm{kHz}$ and the results were good enough to understand the transformation and the temperature effects over the AISI 4340 spline microstructure.

\subsection{Simulation Results}

In "Figure 3", temperature isothermal surfaces are shown to explain the heating penetration depth and the pattern described by the scanning movement. The red region is the region heated the most with more than $900^{\circ} \mathrm{C}$. That region undergoes martensitic transformation after fast quenching. That is the hardened region which will be exposed to stresses and continuous contact with other moving parts in the engine. The light blue region (from $650^{\circ} \mathrm{C}$ to $800^{\circ} \mathrm{C}$ ) undergoes some transformation but not enough to reach austenite form and of course not to reach martensitic form after quenching.

For temperatures below $640^{\circ} \mathrm{C}$, no physical transformations are observed and the material remains in its bulk state. In fact, surface induction hardening process aims to harden the surface that is exposed to external efforts and fatigue and maintain the elastic properties of the spline heart so it will not bend under great pressure.

\subsection{Predicted and Measured Results Comparison}

Four set of simulations were done for validation with four heat-treated specimens. "Table 1", presents the set parameters used in these simulations.

For each set of parameters, a simulation was done and temperature was measured along a line extending from the surface to the core of the spline. Due to the superficial aspect of induction heating, the temperature along this line

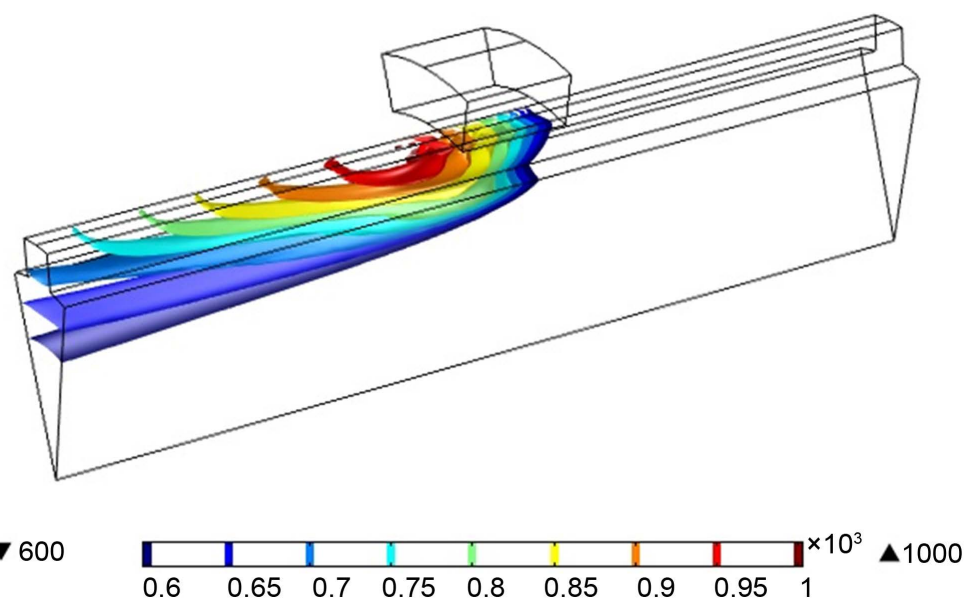

Figure 3. Isothermal surfaces showing different 3D levels. 
starts at its highest value and decreases until all of the induced heat disappears. As the temperature decreases from $1000^{\circ} \mathrm{C}$, it first reaches the level where the austenite formation is completed $\left(d_{s}\right.$ at $A c_{3}=850^{\circ} \mathrm{C}$ ), followed by the level where austenite formation starts $\left(d_{L}\right.$ at $\left.A c_{1}=825^{\circ} \mathrm{C}\right)$, and finally the level where no physical transformation occurs $\left(d_{c}\right.$ at $\left.T_{0}=640^{\circ} \mathrm{C}\right)$. To better visualize the temperature behavior, "Figure 4 " shows temperature variation versus depth in the spline for each set of velocity and power parameters.

The predicted hardened case depth is measured from the intersection of the decreasing temperature curve and the $A c_{3}$ line at $850^{\circ} \mathrm{C}$. Set $\mathrm{A}$, set $\mathrm{B}$, set $\mathrm{C}$, and set $\mathrm{D}$ have case depths of $1.26 \mathrm{~mm}, 1.15 \mathrm{~mm}, 2.134 \mathrm{~mm}$, and $1.92 \mathrm{~mm}$, respectively (see "Figure 4", and "Table 2").

The same sets of parameter values were applied to harden four specimens using induction machine. All four specimens reached martensitic formation after quenching, but with different case depths. For set A, the martensitic region had a case depth of $1.265 \mathrm{~mm}$ from the surface. A good hardened profile is visible and the entire tooth is transformed. For set B, the measured case depth is $0.98 \mathrm{~mm}$, for set $\mathrm{C}$ it is $2.135 \mathrm{~mm}$, and finally for set $\mathrm{D}$ it is $1.914 \mathrm{~mm}$ (see "Figure 5 "). In the next paragraph, a comparison between simulated and measured hardness profiles is carried out for each of the four sets of parameter values. This is done to calculate the error rate and determine the precision and reliability of the $3 \mathrm{D}$ model.

\subsection{Error Calculation and Model Precision}

For each set of parameter values, 3D modeling and simulation using the finite element method and case depths experimental measurement are used to produce the hardness curve versus depth in the spline (see "Figure 6"). Theses curves are used to estimate the deviation between the predicted and the measured hardness and consequently to evaluate the precision and the efficiency of the prediction model.

The AISI 4340 spline has a high core hardness, $H_{C}$, of $350 \mathrm{HV}$, which means that the microstructure is in an unstable martensitic state. From the surface to $d_{s}$

Table 1. Sets A, B, C, and D definition for simulation and validation parameters.

\begin{tabular}{ccc}
\hline & $V=8 \mathrm{~mm} / \mathrm{s}$ & $V=12 \mathrm{~mm} / \mathrm{s}$ \\
\hline$P=24 \mathrm{KW}(40 \%)$ & Set A & Set B \\
$P=28 \mathrm{KW}(44 \%)$ & Set C & Set D \\
\hline
\end{tabular}

Table 2. Hardened depths for the four sets of parameter values.

\begin{tabular}{cccc}
\hline Sets & $d_{s}(\mathrm{~mm})$ & $d_{L}(\mathrm{~mm})$ & $d_{c}(\mathrm{~mm})$ \\
\hline A & 1.260 & 1.680 & 3.200 \\
B & 1.150 & 1.510 & 2.900 \\
C & 2.134 & 2.390 & 3.720 \\
D & 1.920 & 2.200 & 3.300 \\
\hline
\end{tabular}




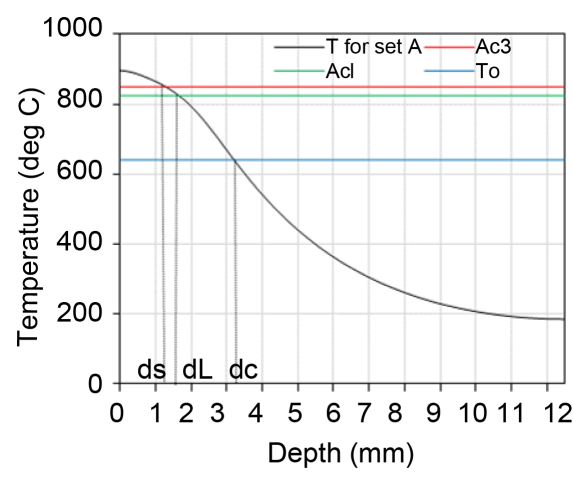

(a)

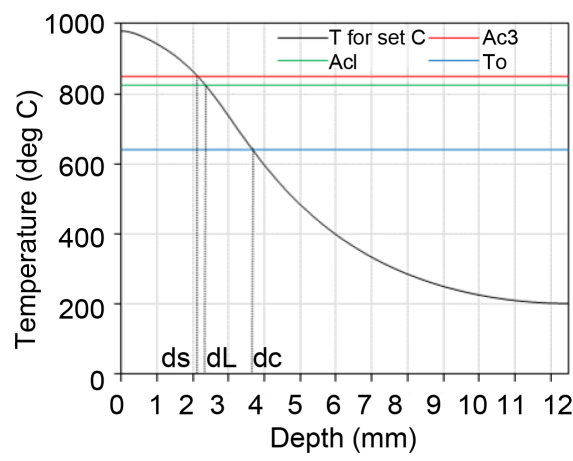

(c)

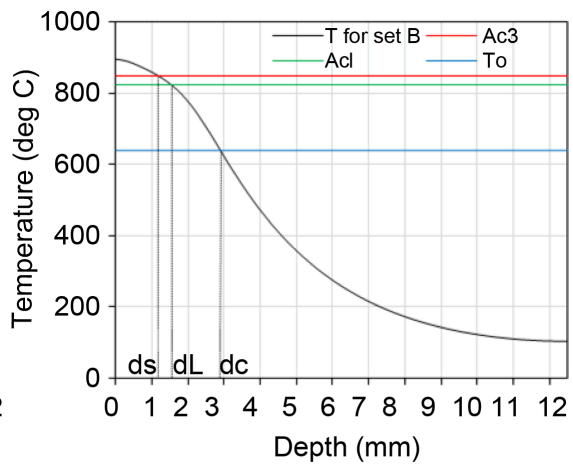

(b)

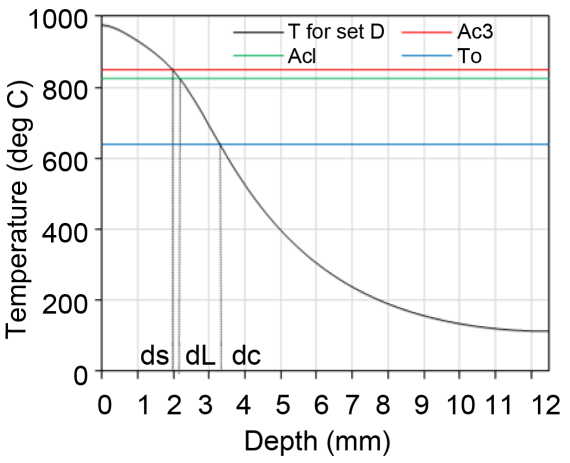

(d)

Figure 4. Temperature versus depth for power and velocity variation for sets (a)-(d).

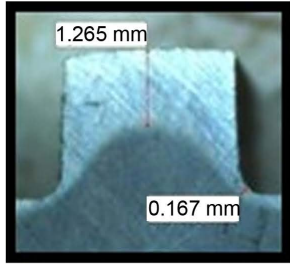

(a)

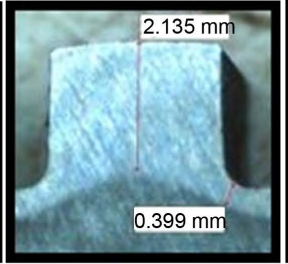

(b)

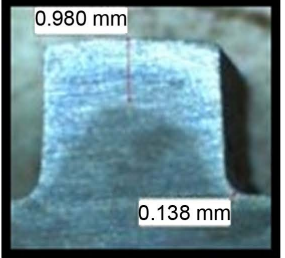

(c)

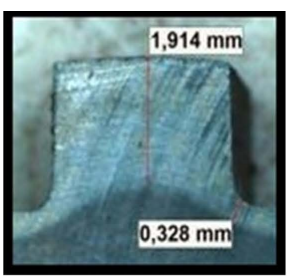

(d)

Figure 5. Hardened specimens for set A, B, C, and D and measurement of the different hardened case depths.

the region is transformed to an austenitic phase because the temperature, $T$, is greater than $A c_{3}$. This region is transformed to a martensitic structure and is characterized by a maximum hardness, $H_{S}$, equal to $650 \mathrm{HV}$. The second region represents loses in hardness and is characterized by a minimum hardness, $H_{L}$, equal to $300 \mathrm{HV}$. The third region is heated but not transformed because the temperature is less than $A c_{1}$. Finally, the fourth region is not affected by any transformation. The case depth is characterized by the first zone, called hard zone. In fact, a case depth at full hardness is interesting to consider as a specification, since there would be a homogeneous microstructure ("Figure 2"), nearly constant hardness, and compressive residual stresses levels [10] [11] [12] [13].

The four regions limits are calculated in "Table 2" for each set of parameter values using "Figure 4". It is sufficient to calculate the $\mathrm{x}$-axis coordinates of the intersections of the temperature curves and the three temperatures, $A c_{3}, A c_{1}$ 


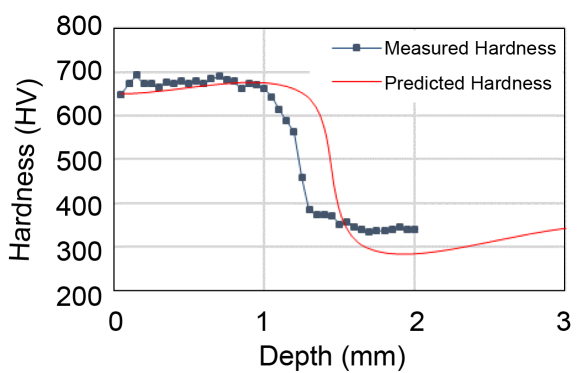

(a)

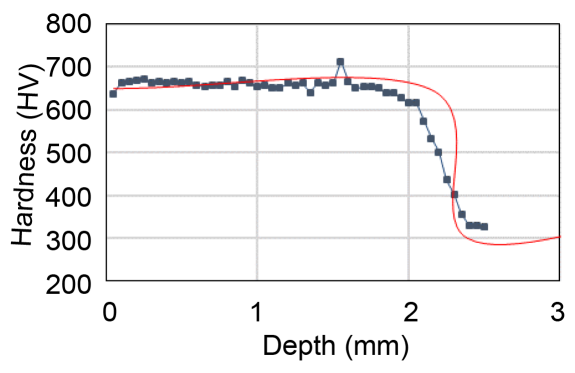

(c)

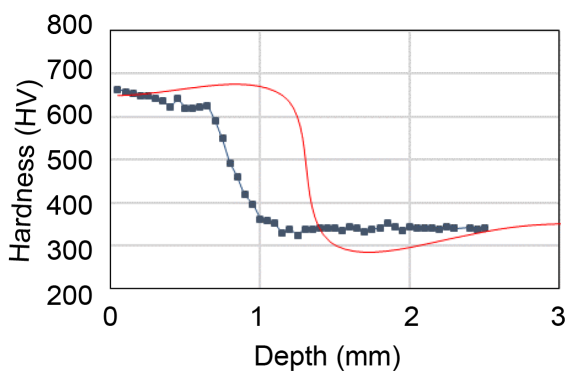

(b)

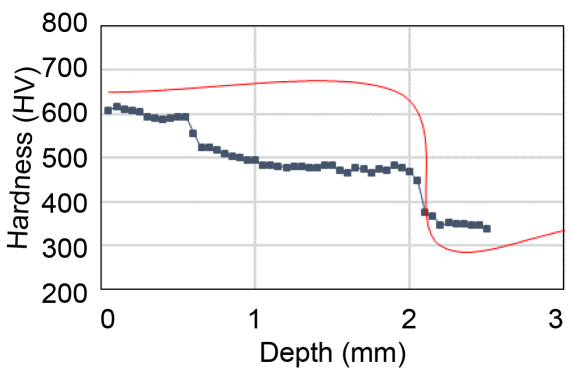

(d)

Figure 6. Predicted and Measured Hardness versus depth for Sets (a)-(d).

and $T_{0} \cdot A c_{3}$ is the temperature above which the material is transformed to austenite $\left(d<d_{S}\right), A c_{1}$ is the temperature at which austenite transformation begins $\left(d_{S}<d<d_{C}\right)$, and $T_{0}$ is the maximum temperature where the AISI 4340 no longer undergoes change in its micro-structure $\left(d>d_{C}\right)$. The first region is where the hardness value is at its maximum. The hardness drops dramatically, to a minimal value equal to $H_{L}$, in the second region where the material tries to affect a reaction opposing the action of heating. In the third region, the hardness increases again to reach an initial value equal to $H_{C}$, which is normal as it is nearer to the core.

The last region represents the material with unaffected microstructure. These three regions are illustrated in "Figure 6". The spline is hardened at the surface, while core hardness does not change, which is normal in the case of surface treatments. The surface of the spline is the region in contact with other components, and therefore the region that will deteriorate first, hence the importance of having maximal hardness on the surface and through the skin depth. The data given in "Table 3" are used to draw the predicted and measured case depths versus sets of parameter values, shown in "Figure 7". In the same figure, error is plotted to allow comparison with the two hardened depths. As we can see, the prediction models are very accurate. However, the predicted hardness in the spline is slightly short, in terms of depth, of the measured hardness only for set B. This is due to experimental measurements: in the simulation, only one twelfth of the spline is studied due to the symmetrical aspect of the model, but when the real spline was treated there were no edges because the spline was not cut, contributing to the miniscule discrepancy. The predicted and measured case depth are shown in the following table, and the error is calculated for each of the four sets. 
Table 3. Simulation versus validation case depths for the four sets of values.

\begin{tabular}{ccccc}
\hline Set & Simulation $(\mathrm{mm})$ & Validation $(\mathrm{mm})$ & Error $(\mathrm{mm})$ & Error $(\%)$ \\
\hline A & 1.260 & 1.265 & 0.005 & 0.395 \\
B & 1.150 & 0.980 & 0.170 & 17.347 \\
C & 2.134 & 2.135 & 0.001 & 0.047 \\
D & 1.920 & 1.914 & 0.006 & 0.313 \\
\hline
\end{tabular}

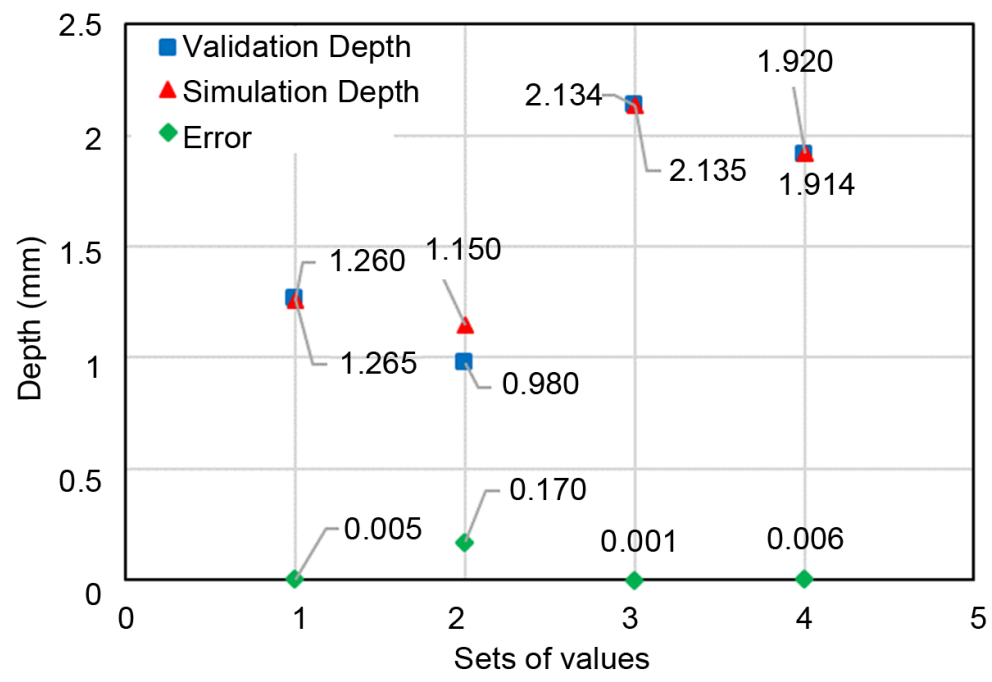

Figure 7. Predicted and measured case Depths, and errors versus Sets of values.

The best set result is for set $\mathrm{C}$, as the drop in hardness is nearly identical for the predicted and measured cases. For a velocity $V=8 \mathrm{~mm} / \mathrm{s}, P=44 \%$, and a frequency of $200 \mathrm{kHz}$, error is equal to $0.001 \mathrm{~mm}$. These parameters thus prove a perfect combination for a perfect surface layer of martensite. This set can therefore be used for the sensitivity study in the following section.

\section{Sensitivity Study and Behavioral Equations}

A sensitivity study was conducted to determine the behavior of temperature as a function of frequency, power, and scanning velocity. One of the goals of such a study is to understand the influence of each parameter over the temperature. The contribution of each parameter was measured as a percentage. Frequency, power, and scanning velocity were changed between five levels, called scratching levels. ANOVA was used to establish the nonlinear equations describing temperature as a function of each parameter. This method helps to obtain the effects, relative weights, and relationships between the different process parameters.

\subsection{Scratching Parameters Choice and Variation}

The degree of variation for frequency, power and scanning velocity were, respectively, $10 \mathrm{kHz}, 1 \%$, and $1 \mathrm{~mm} / \mathrm{s}$. "Table 4" shows the scratching levels used in the sensitivity study. To analyze the effects, "Figure 8", shows the mean tem- 
perature versus scratching parameters for each of the process parameters varied during the simulations and the tests.

\subsection{Results and Interpretation}

The effect of frequency over temperature is weak compared to the effects of power and velocity. In fact, a variation of $\pm 10 \mathrm{kHz}$ in frequency leads to nearly \pm $25^{\circ} \mathrm{C}$. The calculated percent contribution of frequency to temperature is equal to $13.264 \%$, as shown in "Table 5". This weak effect is due to the fact that frequency is most responsible for skin depth and the penetration ratio. The frequency is only found in the equation for skin depth in the theoretical study of induction heating [3] [4]. Concerning power, a variation of $\pm 1 \%$ leads to a variation of $\pm 40^{\circ} \mathrm{C}$; the contribution is equal to $18.840 \%$. The most influential process parameter is the scanning velocity. For low velocities at level 1 and level 2, an increase of $1 \mathrm{~mm} / \mathrm{s}$ makes the temperature drop by nearly $75^{\circ} \mathrm{C}$. For level 4 and level 5 the drop is less drastic, with temperature decreasing only by $40^{\circ} \mathrm{C}$. This is due to the fact that the faster the spline is moving, the less time it is exposed to the electromagnetic fields induced from the coil, and therefore the lower is the temperature. For scanning induction heating process, researchers must study the scanning speed very carefully to better chose the most appropriate value needed for each individual application. The frequency value is most crucial when locally

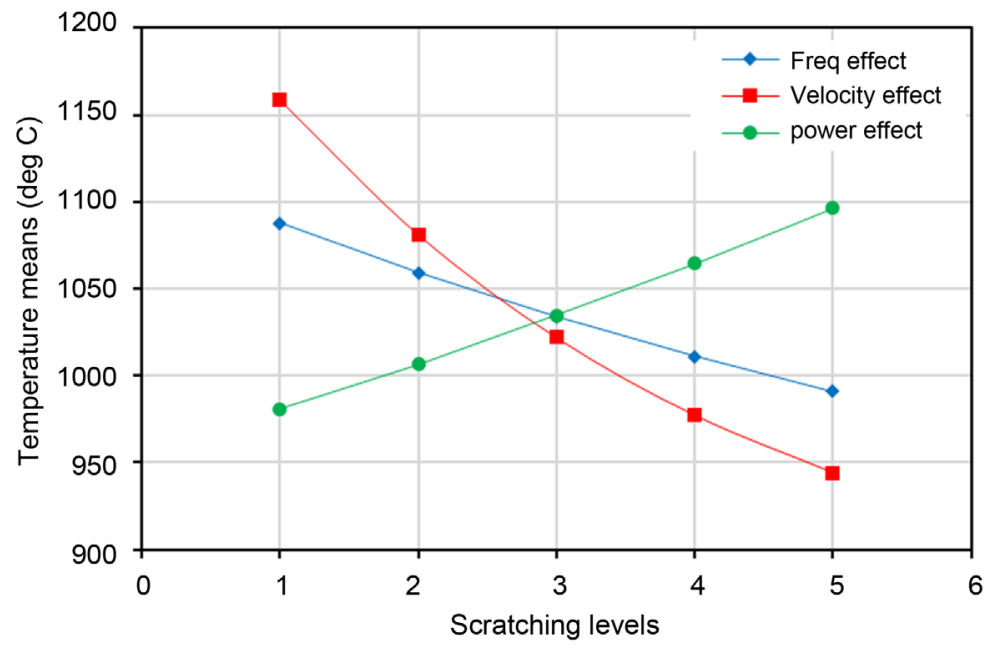

Figure 8. Temperature means versus Scratching parameters for the frequency, the power, and the scanning velocity.

Table 4. Scratching parameters and their levels for the sensitivity study.

\begin{tabular}{cccccc}
\hline \multirow{2}{*}{ Factors } & \multicolumn{5}{c}{ Scratching levels } \\
\cline { 2 - 6 } & 1 & 2 & 3 & 4 & 5 \\
\hline$f(\mathrm{kHz})$ & 180 & 190 & 200 & 210 & 220 \\
$P(\%)$ & 42 & 43 & 44 & 45 & 46 \\
$V(\mathrm{~mm} / \mathrm{s})$ & 6 & 7 & 8 & 9 & 10 \\
\hline
\end{tabular}


Table 5. Percent contribution of each parameter variation over the temperature.

\begin{tabular}{ccccc}
\hline & $f$ & $P$ & $V$ & Error \\
\hline$T$ & 13.26 & 18.84 & 65.79 & 2.11 \\
\hline
\end{tabular}

heating a mechanical component in which the dimension of the martensitic layer is the most important. Stationary induction heating of splines and gears is a good example for better understanding the effects of frequency, as the equal heating of tips and roots constitutes a great challenge [3] [4].

Concerning the power induced in the piece, the role of power has the same importance in every application. "Table 5 " shows the contribution of machine parameters to temperature, calculated using the statistical software Minitab.

\subsection{Behavioral Equations}

In this study, data are implemented and used to find the equations that best describe the relationship between spline induction heating process responses and parameters. The equations link temperature, $T$, and the process parameters in their first, second, and third orders to best determine the nonlinearity of the model. The software used to calculate these equations is Minitab. The equation that links $T$ to frequency, power and scanning velocity can be written as shown in Equation (14), for a linear form, and Equation (15), for a non-linear form.

$$
\begin{aligned}
T & =676.2-2.42 \cdot f-53302 \cdot V+28.88 \cdot P \\
T= & -2336-4.08 \cdot f-77149 \cdot V+112.6 \cdot P \\
& +418.4 \cdot f \cdot V-0.2237 \cdot f \cdot P-4867 \cdot P \cdot V
\end{aligned}
$$

Equation (14) presents the model based on linear regression and allows the evaluation of the case depth as a function of the three factors used in the sensitivity study. On the other hand, Equation (15) presents the model based on a non-linear regression study and includes the interaction between all of the factors. These equations are without units because they involve parameters with different physical aspects and different International System units. They are only used to calculate values. The third degree polynomial equations that best describe the temperature evolution using frequency, power and scanning velocity separately are given below.

$$
\begin{gathered}
T=2571-15 \cdot f+0.05 \cdot f^{2}-6 \times 10^{-5} \cdot f^{3} \\
T=2603-119 \cdot P+2 \cdot P^{2}-0.01 \cdot P^{3} \\
T=2187-2.7466 \times 10^{5} \cdot V+2.05 \times 10^{7} \cdot V^{2}-5.457 \times 10^{8} \cdot V^{3}
\end{gathered}
$$

As can be seen in Equations (16), (17), and (18), the coefficients are much higher when comparing the scanning velocity and the frequency $\left(5.457 \times 10^{8}>6 \times 10^{-5}\right.$ for the third order, $2.05 \times 10^{7}>0.05$ for the second order, and $2.7466 \times 10^{5}>15$ for the first order). Finally, a study of predicted versus measured case depth was done to determine the similarity of the results and the precision of the model. "Figure 9", shows the predicted case depth versus the measured and validated case depth. The line in this figure shows the behavior of 


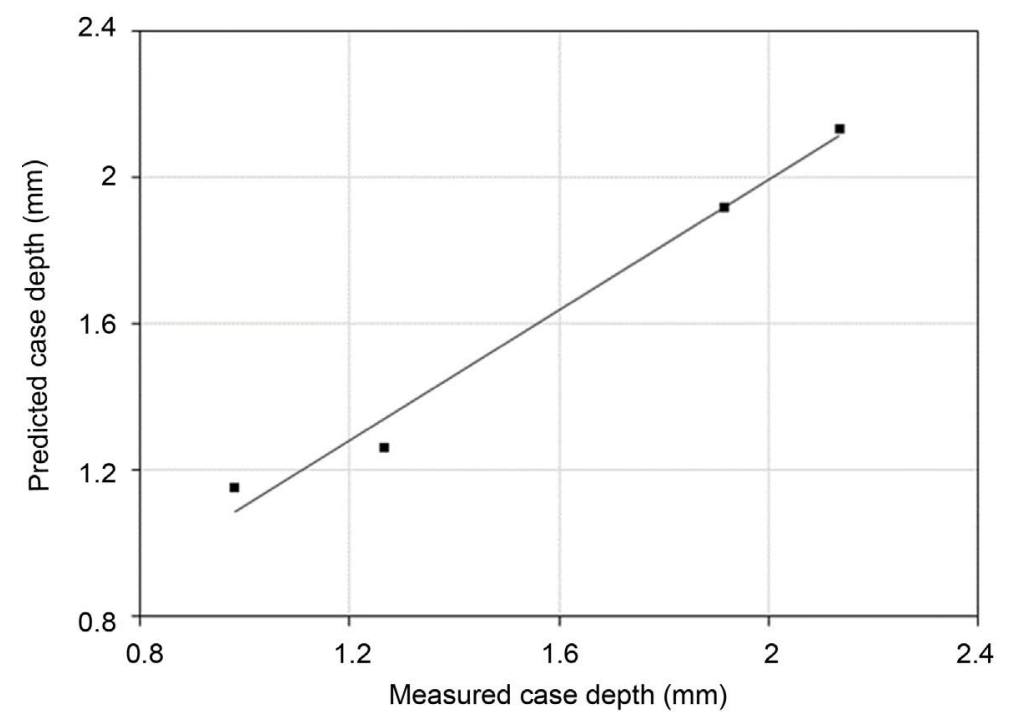

Figure 9. Predicted case depth versus Measured case depth.

predicted case depth versus measured case depth. This line has a linear equation that can be written as follows:

$$
\mathrm{C}_{\text {Depth-Predicted }}=0.2178+0.888 \cdot \mathrm{C}_{\text {Depth-Measured }}
$$

\section{Conclusion}

The mechanical attributes of the hardened surface achieved by induction heating process are influenced by physical and chemical properties of the treated material and several induction heating parameters and conditions. To be able to use correctly the resources offered in this process, it is necessary to develop a comprehensive strategy to control the heating parameters in order to produce the desired hardened surface characteristics for a specific application. Current practices in the industry are based on the control of the induction heating process using the traditional and fastidious trial and error procedures for every single specific part. Based on correlation analysis between various induction heating parameters and final hardness profile developed in the case of stationary induction heating, this paper presents an investigation of non-stationary heating process. The approach proposed in this study focuses on the effects of power, frequency variation and especially scanning speed analysis through extensive 3D modelling and simulation, structured experimental efforts and improved statistical analysis tools. Based on coupled electromagnetic and thermal fields analysis, the developed 3D model is used to estimate the temperature distribution as well as the hardness profile attributes. ANOVA is used to evaluate the contribution of each parameter in temperature and hardness profile attributes variations. Experimentations conducted on a commercial dual-frequency induction machine for AISI 4340 steel splines confirm the feasibility and the validity of the proposed approach. The validation results reveal a great concordance between simulated and measured profiles and confirm that the model can effectively be used as simulation framework for understanding the process and for assessing 
the effects of various parameters on the hardening process quality and performance leading consequently to the most relevant variables to use in an eventual hardness profile prediction model.

\section{References}

[1] Jomaa, W., Songmene, V. and Bocher, P. (2013) On Residual Stress Changes after Orthogonal Machining of Induction Hardened AISI 4340 Steel. Proceedings of Materials Science and Technology Conference and Exhibition, MS\&T 13, 94-103.

[2] Grum, J. (2000) Measuring and Analysis of Residual Stresses after Induction Hardening and Grinding. Materials Science Forum, 347, 453-458.

https://doi.org/10.4028/www.scientific.net/MSF.347-349.453

[3] Hammi, H., Barka, N. and El Ouafi, A. (2015) Effects of Induction Heating Process Parameters on Hardness Profile of 4340 Steel Bearing Shoulder Using 2D Axisymmetric Model. International Journal of Engineering and Innovative Technology, 4, 41-48.

[4] Hammi, H., El Ouafi, A. and Barka, N. (2016) Study of Frequency Effects on Hardness Profile of Spline Shaft Heat-Treated by Induction. Journal of Materials Science and Chemical Engineering, 4, 1-9. https://doi.org/10.4236/msce.2016.43001

[5] Sadeghipour, K., Dopkin, J.A. and Li, K. (1996) A Computer Aided Finite Element/ Experimental Analysis of Induction Heating Process of Steel. Computers in Industry, 28, 195-205. https://doi.org/10.1016/0166-3615(95)00072-0

[6] Boadi, A., Tsuchida, Y., Todaka, T. and Enokizono, M. (2005) Designing of Suitable Construction of High-Frequency Induction Heating Coil by Using Finite-Element Method. IEEE Transactions on Magnetics, 41, 4048-4050. https://doi.org/10.1109/TMAG.2005.854993

[7] Zabett, A. and Mohamadi Azghandi, S.H. (2012) Simulation of Induction Tempering Process of Carbon Steel Using Finite Element Method. Materials \& Design, 36, 415-420. https://doi.org/10.1016/j.matdes.2011.10.052

[8] Magnabosco, I., Ferro, P., Tiziani, A. and Bonollo, F. (2006) Induction Heat Treatment of a ISO C45 Steel Bar: Experimental and Numerical Analysis. Computational Materials Science, 35, 98-106. https://doi.org/10.1016/j.commatsci.2005.03.010

[9] Di Luozzo, N., Fontana, M. and Arcondo, B. (2012) Modelling of Induction Heating of Carbon Steel Tubes: Mathematical Analysis, Numerical Simulation and Validation. Journal of Alloys and Compounds, 536, S564-S568. https://doi.org/10.1016/j.jallcom.2011.12.084

[10] Barka, N., El Ouafi, A.E., Chebak, A., Bocher, P. and Brousseau, J. (2012) Study of Induction Heating Process Applied to Internal Gear Using 3D Model. Applied Mechanics and Materials, 232, 730-735. https://doi.org/10.4028/www.scientific.net/AMM.232.730

[11] Savaria, V., Bridier, F. and Bocher, P. (2012) Computational Quantification and Correction of the Errors Induced by Layer Removal for Subsurface Residual Stress Measurements. International Journal of Mechanical Sciences, 64, 184-195. https://doi.org/10.1016/j.ijmecsci.2012.07.003

[12] Favennec, Y., Labbé, V. and Bay, F. (2003) Induction Heating Processes Optimization a General Optimal Control Approach. Journal of Computational Physics, 187, 68-94. https://doi.org/10.1016/S0021-9991(03)00081-0

[13] Naar, R. and Bay, F. (2013) Numerical Optimisation for Induction Heat Treatment Processes. Applied Mathematical Modelling, 37, 2074-2085.

https://doi.org/10.1016/j.apm.2012.04.058 
Submit or recommend next manuscript to SCIRP and we will provide best service for you:

Accepting pre-submission inquiries through Email, Facebook, LinkedIn, Twitter, etc. A wide selection of journals (inclusive of 9 subjects, more than 200 journals)

Providing 24-hour high-quality service

User-friendly online submission system

Fair and swift peer-review system

Efficient typesetting and proofreading procedure

Display of the result of downloads and visits, as well as the number of cited articles Maximum dissemination of your research work

Submit your manuscript at: http://papersubmission.scirp.org/

Or contact ampc@scirp.org 